\title{
Proposed guidance for developing ecohydrological models
}

\author{
$\underline{\text { Carmel A. Pollino }}^{\text {a }}$, Danial Stratford ${ }^{\text {a }}$, Serena H. Hamilton ${ }^{\mathrm{b}}$ and Emily Barbour $^{\mathrm{c}}$ \\ ${ }^{a}$ CSIRO Land and Water, Canberra, ACT 2601, Australia \\ ${ }^{b}$ Edith Cowan University, Joondalup, WA 6027, Australia. \\ ${ }^{c}$ University of Oxford, Oxford, OX1 3QY, United Kingdom \\ Email: Carmel.Pollino@,csiro.au
}

\begin{abstract}
Water resource development, including infrastructure and extraction, has long been recognized to change water-dependent species, populations, their habitats and supporting processes. Management of the flow in rivers through environmental flows is one way to limit adverse environmental change. Environmental flows describe the quantity, timing and quality of water to support ecosystems and the human livelihoods that are reliant on these.

Since the formalisation of environmental flow science in the late 1940's, a range of environmental flow frameworks have been developed ranging from the simple to the complex, from hydrological to socioecological systems-based approaches. The development of ecohydrological models has been a critical part of such frameworks, with many applications presented in the literature. Such a broad range of applications has created a rich variety of ecohydrological models that are available for researchers and practitioners to choose from. However, there are many aspects to this decision process that are required to ensure the approach taken is fit for the intended purpose. Whilst there is a rich literature of ecohydrological frameworks and modelling approaches, to date there have been few attempts to guide practitioners in how to go about selecting the most appropriate ecohydrological model to suite their purpose. This paper is intended to guide practitioners in their decisions for ecohydrological modelling.
\end{abstract}

We contend that the selection and development of ecohydrological models is based on the following key questions:

- What is the model purpose?

- Over what scales does the model need to be applied?

- What is the 'right' balance of model uncertainty and credibility?

- What are the choice of indicators, given purpose and scale?

- What are common ecohydrological modeling approaches that are available?

In this paper, we discuss each of these considerations, with examples drawn from the Murray-Darling Basin. We discuss how different modeling families are often applied in a context of assessing environmental flows given their underlying structure, data requirements and the level of uncertainty, noting the various sources of uncertainty and how this relates to fit for purpose modelling in a management context.

Keywords: Ecohydrology, guidance, ecology, environmental flows 


\section{INTRODUCTION}

River flows in channels and on floodplains structure both physical and biological environments. Flow patterns and connectivity between river channels, wetlands and floodplains are essential to the viability of many water dependent species (Bunn and Arthington 2002), leading to characteristic high biodiversity. Flow is a key determinant in structuring ecology and vice versa (Ward et al. 1999).

The dynamics of river and floodplain connections promote ecological processes through the exchange of matter and organisms. Variations in the magnitude and spatial extent of flood-mediated disturbances creates habitats that are characterised by stages of succession, resulting in dynamic and diverse water-dependent species and habitats across floodplains (Whited et al. 2007). The habitat of floodplains is a diverse mosaic of species, communities and populations across rivers and their floodplains (Ward et al. 1999, Merritt et al. 2010). Indeed, the distribution and age of river-floodplain complexes reflects a legacy of hydrologic conditions, from large scouring floods that create expansive areas for recruitment, to extended periods of moderate to low disturbance that promote succession (Whited et al. 2007).

River management has disrupted riverine and floodplain ecology by altering their connectivity and fragmenting and isolating communities across the landscape, invariably leading to changes in composition of biodiversity and ecological processes (Ward et al. 1999). Ecological processes in river ecosystems are heavily influenced by many facets of a dynamic, historical flow regime (Poff et al. 1997, Bunn and Arthington 2002).

An extensive range of modelling approaches and tools have been developed to assess ecological outcomes of flow regimes. Many environmental flow assessments have a foundation in the natural flow paradigm (Poff et al. 1997, Richter et al. 1997), identifying components of natural flow variability important to maintain ecosystems. Key attributes of the flow regime are the magnitude, frequency, timing, duration, rate of change and predictability of flow events, and the sequencing of such conditions needs to be considered in protecting rivers and floodplains (Poff et al. 1997, Arthington et al. 2006). The rapid acceptance of the natural flow regime paradigm has been accompanied by an expectation that ecologists can easily provide specific environmental flow prescriptions for riverine ecosystems (Poff et al. 2010). However, translating general hydrologicecological principles and knowledge into specific management rules for particular river basins and reaches remains a daunting challenge (Poff et al. 2010). Environmental flow assessments, and modelling that underpins these, are one avenue to achieve this. Here, we focus on steps we contend are useful for developing ecohydrological models.

\section{GUIDANCE FOR ECOHYDROLOGICAL MODELLING}

There is significant difficulty in selecting a suitable approach for ecohydrological modeling. The questions posed below are what we contend as critical in model selection for ecohydrological assessments. These questions represent the first four steps for selecting a modelling approach that is fit for purpose. To do this, we draw from the first four steps in the Ten Steps for the development and evaluation of environmental models (Jakeman et al. 2006). The remaining steps are critical for model evaluation and iterate back to development, but we do not discuss that in this paper.

\section{Question 1: What is the model purpose?}

Ecohydrology models can be used for a range of purposes, including to: frame problems; explore system behavior; explore scenarios; reveal gaps in understanding and data; explore the sensitivity of decisions to assumptions (and how it affects decision making); and to guide decision options.

Defining the model purpose is essential for choices made in the subsequent modelling steps. This can involve understanding the context in which the model is being developed, the decision environment, including the stakeholders involved in the process, and the scales over which the model is to be applied.

Ecohydrological models typically explore ecological change where flow is a major driver of change. They are used to summarise the state of knowledge of dependencies between flow and ecology including the sensitivity of ecology to flow change, and in providing guidance for management and decision-making, including in investments in future monitoring or in structural or policy interventions. Typically the purpose of an ecohydrological model is not any one of these, but an intersection of these. Although, it is worth noting that many ecohydrological models are built within a decision-context (Poff et al. 2010).

Choosing a model that is fit-for-purpose requires an understanding of whether a generalisable or specific solution is needed. A generalizable solution aims for being applicable across a broad area where in contrast, a specific solution is one that is focused on a certain place or target species. Across large areas, a generalisable approach limits bias through promoting consistency, although there are some methodological constraints. This 
was the case in evaluating an adjustment to the Sustainable Diversion Limit underpinning the Murray-Darling Basin Plan, which had such a requirement for generality (Overton et al. 2014). The approach used a limited set of causal factors and drew upon a broad base of literature as underpinning evidence, whilst attempting to limit knowledge bias. This is contrast to a specific, often catchment, place or species-specific assessments, which are often data-based and can often represent a greater complexity of system drivers (for example (Kingsford and Auld 2005)). Although the specific models tend to have limited capacity for extrapolation, this capacity can be assessed with model evaluation approaches such as cross validation (Elith and Leathwick 2009).

Basin-scale assessments pose challenges in selecting 'fit-for-purpose' modelling approaches. This is particularly in evaluating decisions that involve trade-offs between places. Selecting methods that can span across extensive spatial scales, whilst underpinning models with best available evidence and avoiding bias by having detailed information in one place, is a problem rarely addressed in the literature. We address this further in Question 2.

The degree of abstraction in choosing a model that can address the objectives is a choice. In particular, the complexity of the model should be consistent with both the purpose as well as the state of knowledge (Question 4 deals with this in more detail). While many trade-offs exist in evaluating whether a model approach is 'fit for purpose', a model that is considered either too simple or too complex can represent a failure to appropriately understand and represent the problem domain or decision context (Addison et al. 2013).

\section{Question 2: Over what scales does the model need to be applied?}

Life history strategies of biota are often viewed in terms of spatial and temporal habitat availability, and the predictability and condition of these (Southwood 1977). Flow variability occurs over a wide range of temporal scales, and this variability is strongly linked to the structure and function of ecosystems (Biggs et al. 2005) that can be represented as a nested spatial hierarchy (Biggs et al. 2005). Hierarchies of scale apply to hydrological scales, and are defined as Basin $>$ Catchment $>$ Reach $>$ Site, whereas ecological scales range from Geographic $>$ Population $>$ Habitat $>$ Patch $>$ Micro-site.

The Basin-scale represents a mosaic of habitats and meta-populations which they support, and can be used to assess the cumulative impacts of management, or as an integration point, where a range of drivers are considered (Frissell et al. 1986). At a policy-scale or planning scale, the Basin is a hydrologically connected system, where governance mechanisms apply at the whole of Basin. Flow averages or simple ranges are often used to describe hydrology. Catchment and reach scales are useful scales for determining medium to long-term effects of human activities on the flow regime (Frissell et al. 1986). The site-scale is defined by a pool and riffle system, described by water depth, velocity, slope and bed topography. Microhabitats occur as patches within pool/riffle zones, and are relatively homogenous in their characteristics, such as the substrate type, depth and velocity (Frissell et al. 1986).

High volume flow events at low frequency over prolonged temporal scales have a strong influence on structuring both community compositions and functions. This contrasts with more frequent and less intense events which affects the life history of individuals (Biggs et al. 2005). Typically, long-term changes in flow magnitude, duration, timing and frequency is believed to define physical habitat over sub-catchment to catchment spatial scales, short-term histories of hydrologic events are believed to influence habitats at reach to within-reach scales (Kennard et al. 2007). Together, these factors influence the availability of food resources, refuges, movement and migration triggers, and conditions required to fulfil requirements of a diversity of biota (Kennard et al. 2007).

The ability to model hierarchical linkages, such as trophic chains, within ecosystems is challenging. Complex trophic interactions are poorly understood and models are difficult to validate. Consequently, relationships are largely expressed as hypotheses, theory or conceptual representations, rather than predictive or quantitative models (Kennard et al. 2007). Whilst exploring interactions is a challenge, our ability to model within hierarchies is improving, using approaches such as graph theoretic approaches and trophodynamic models (Plagányi et al. 2011). A challenge remains in how to quantitatively validate these models.

\section{Question 3: What is the 'right' balance of model uncertainty and credibility?}

Uncertainties present a challenge to environmental policymakers and managers who are charged with making decisions about how our natural systems are to be exploited and protected. The level of uncertainty associated with knowledge is reflective of the information source, the use of qualitative and quantitative information, the quality and coverage of data to develop the model, and the degree of representation of systems complexities, such as feedbacks or multivariate responses. As discussed below, there is a broad range of model approaches that can be used in environmental flows, ranging from simple to complex. The decision on the level of 
Pollino et al., Ecohydrological modelling: guidance on selecting approaches

acceptable uncertainty in decisions is often related to: where the risks or responsibilities for uncertainty lie; the variability or sensitivity of outcomes given uncertainty; and the implications, including the impacts or costs associated with decisions, such as actions to mitigate any risks to market and non-market economies. The uncertainties represented in these vary, and so too does the model credibility

Credibility of the model is related to the amount of knowledge available, the purpose of the model, the consequences or risks of use for incorrect decisions (Rykiel 1996) and the model transparency. The credibility of the model is typically part of the evaluation of the model, and explored further in the Jakeman et al. (2006), but it is critical to define the level of confidence needed in the model development. The level of acceptable model credibility varies according to the model purpose. For example, a model used for exploring the behaviour and emergent properties of a complex system which is largely theoretical, contrasts with a model used to set and evaluate environmental flow requirements or sustainable diversion limits, which may be required as part of a water planning framework.

The credibility of a model is a critical decision in model development. How faithfully does the model need to represent the system being analysed? Is it in representing all system drivers or only those subject to management? Is the model sufficiently believable to justify further action? If so, what line is evidence can be used? What parameterization techniques should we apply? Can qualitative inputs be used, is theoretical understanding sufficient? Does the model need independent quantitative verification?

As a general rule of thumb, simpler models tend to have fewer assumptions and are easier to validate. Whilst these models are more transparent and therefore more credible to a decision-makers. However, they have limited representation of complexity, such as interacting drivers, and feedbacks, which increases uncertainties. Complex models can be difficult to validate, with relationships often being more theoretical.

\section{Question 4: What are the choice of indicators, given purpose and scale?}

After defining the model purpose and scale, the next question relates to representation of the features and processes to be considered in the model. Understanding the essential model features guides the selection of modelled indictors, model inputs and the choice of model type.

Here we describe model indicators as representing aspects of the system that are specific, measurable or observable to change, showing progress to meeting a particular objective. In selecting indicators, some options are:

- Functional groups - communities of species that are likely to have similar needs and responses to change

- Umbrella species - species that share habitat

- Indicator species - a common species that reflects the presence, absence or condition of a broader ecosystem

- Populations of a species - survival, births, deaths, growth resulting in number of individuals

- Habitat suitability or condition - climate, hydrological, water quality, connectivity parameters

- Food webs - interacting trophic levels

Umbrella species or functional groups are considered an advance from single species approaches, being more representative of the broader ecological communities. This approach suffers from limitations in only having a limited representation of the mechanisms that cause fluctuations in population and this approach may fail to conserve a species or process outside of the 'umbrella' (Poiani, et al. 2000). However, by incorporating multiple functional groups or umbrella species into the method, and selecting a broad range of non-overlapping species or different functional groups, there is a potential to minimise this bias and increase representation. An umbrella ecosystems approach was used in establishing the Environmental Water Requirements underpinning the Murray-Darling Basin Plan, where places rather than species were used to represent water requirements of the Basin (Swirepik et al. 2016).

Model indicators represent salient features of the ecosystem, with the choice of these guided by the model purpose. We propose a suite of hydrological and ecological indicators across spatial and temporal scales (Table 1). We have indicated both hydrological indicators that can be used as a surrogate for ecological responses, as well as potential ecological indicators. The scales represent the typical scales at which you would use for that indicator. 
Pollino et al., Ecohydrological modelling: guidance on selecting approaches

Table 1. Proposed selection of indicators, which are dependent on scale of interest

\begin{tabular}{|c|c|c|c|}
\hline Spatial Scale & Hydrological indicator & Ecological indicator & Scale of change \\
\hline Basin & Connectivity & $\begin{array}{c}\text { Metapopulations, Patterns, } \\
\text { Mosaics }\end{array}$ & $\begin{array}{l}\text { Decadal to Inter- } \\
\text { Decadal }\end{array}$ \\
\hline Catchment & Regime & $\begin{array}{c}\text { Disturbance, Patterns, Mosaics, } \\
\text { Biotic exchanges, Populations, } \\
\text { Communities or Functional } \\
\text { Groups, Diversity or } \\
\text { Composition, }\end{array}$ & \multirow[t]{2}{*}{$\begin{array}{l}\text { Decadal to Inter- } \\
\text { decadal, Annual }\end{array}$} \\
\hline Reach & $\begin{array}{l}\text { Flow regime; Flow events- } \\
\text { hydrologic or hydraulic }\end{array}$ & $\begin{array}{l}\text { Populations, Communities or } \\
\text { Functional Groups, Diversity or } \\
\text { Composition, Condition }\end{array}$ & \\
\hline Site-scale & \multirow[t]{2}{*}{$\begin{array}{c}\text { Flow events- hydrologic or } \\
\text { hydraulic }\end{array}$} & $\begin{array}{c}\text { Species diversity, Persistence, } \\
\text { Biomass, Habitat }\end{array}$ & \multirow[t]{2}{*}{$\begin{array}{l}\text { Annual and Inter- } \\
\text { annual, Days, Months }\end{array}$} \\
\hline Micro-scale & & Biotic processes, Habitat & \\
\hline
\end{tabular}

\section{Question 5: What are common ecohydrological modeling approaches that are available?}

The selection of a model type or approach is key to representing essential features of scales, indicators and model inputs. Here we overview the more common ecohydrological modelling approaches, which are typically used in planning contexts.

Hydrologic methods rely primarily on flow measures and indices drawn from historical time series data and are regarded as the simplest approach to determining environmental flow requirements (Tharme 2003). These methods rely primarily on the statistical analysis or summary of time series, and explore percentage changes in flow. They are typically used to compare a 'natural' or baseline flow, to an altered flow, derived using flow data or from models often through scenario analysis. The outputs can be used to make recommendations on flow requirements.

Defining a "minimum" flow recommendation is widely regarded as inadequate in maintaining the structure and function of a riverine ecosystem (Arthington et al. 2006). Hydrological methods can also be used to derive flow metrics, which summarise a time series of flow, characterising events or the flow regime. Common metrics used for assessing flow alterations are characterised as flow magnitudes or minimums, frequency, duration, timing and rate of change, and flow sequencing (Poff, et al. 1997, Poff and Zimmerman 2010). These indicators can be used as surrogates of ecological response or as inputs to ecological models. Like hydrological methods, hydraulic methods use changes in simple hydraulic variables, such as velocity, wetted perimeter or maximum depth as a surrogate for habitat factors known or assumed to be limiting for target biota.

Habitat Suitability Models are a simpler form of habitat models. They are often used to represent the habitat conditions that influence the presence, abundance and distributions of organisms in the environment (Southwood 1977). They can be used to predict species occurrences on the basis of abiotic and biotic variables and to represent habitat requirements (Ahmadi-Nedushan et al. 2006), as described below. The Ecological Niche Model depicts a species habitat using environmental limitations (Kearney and Porter 2009). These are often called Species Distribution Models (SDMs) and are used to make inferences on actual or potential species range limits and associated habitat suitability, via identification of their environmental requirements (Kearney and Porter 2009, Soberón and Nakamura 2009). A typical output is a habitat suitability map or distribution.

A simpler form of habitat models is Habitat Suitability Indices (HSIs) (Burgman et al. 2001). These are an analytical tool used to represent preferences of different species for various habitat variables. A HSI represents a form of conceptual model that relates a measurable variable to the suitability of a site to a species (Burgman et al. 2001). They are often constructed using expert opinion, which may be informed by habitat use data (Bovee 1982). Suitability can be expressed as a curve (e.g. probability of use or preference curve) that specifies the assumed seasonal requirements of different species, life stages or habitat guilds. Curves are used to depict the relationship of a target organism's response to a gradual changing habitat variable, such as a flow indicator, scaling from unsuitable to suitable, typically expressed as an index ranging from 0 to 1 . A more complex form of a HSI model is a State and Transitions Model. 
Population Models are dynamic models that represent dynamic change, where the persistence or abundance of a population at a given location depends on the balance between births and deaths, and immigration and emigration. Population viability analysis is an early adopted approach for modelling, where a minimum population size to main a particular species over time is estimated (Ruggiero et al. 1994). Population matrix (age-structured) models are used to determine the influence of the flow regime on dynamic population change. Knowledge of the structure (i.e. age- or size-class distributions) of a population is required. Age-class distributions can provide insight into event-driven recruitment, identifying the influence hydrologic characteristics and regimes provide for the requirements of a range of species (Merritt et al. 2010). Whilst short-lived species, such as annual aquatic vegetation, could respond on the scale of a single season, longerlived species, such as riparian vegetation, could require decades or even centuries to respond. A trophic model is typically a more complex dynamic model, which are often based on theoretical relationships.

This is not an exhaustive list of modelling approaches, but rather an overview of typical approaches used in basin planning that are part of a diversity of modelling approaches, which range in complexity and data requirements (Error! Reference source not found.).

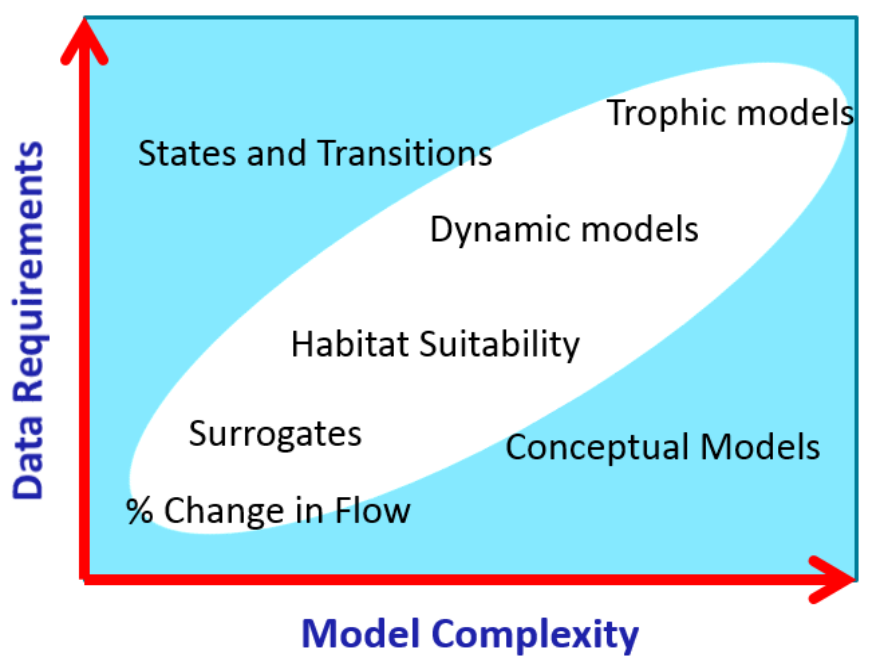

Figure 1. Typical modelling approaches, which range in complexity and data requirements

\section{DEFINING GOOD PRACTICE FOR ECOHYDROLOGICAL MODELS}

Ecohydrological models typically bridge decision-making and science. Their use in decision making puts a high demand on scientists in circumstances where knowledge is incomplete, data is patchy or absent, and investment in the underpinning science is limited or absent. To counteract this, science poses solutions within an adaptive framework, where uncertainty is part of the decision process. Solutions can also be either too general with high uncertainties, or too specific or narrow with no broad applicability. Ecohydrological models can assist in increasing the credibility, saliency and legitimacy of science within decision contexts, when the model selected is 'fit for purpose'. Given the high demand on ecohydrological models in decision contexts, we believe that formalizing of good practice will assist practioners in making wise model choices.

\section{REFERENCES}

Addison, P. F. E., L. Rumpff, S. S. Bau, J. M. Carey, Y. E. Chee, F. C. Jarrad, M. F. McBride, and M. A. Burgman. (2013). Practical solutions for making models indispensable in conservation decisionmaking. Diversity and Distributions 19:490-502.

Ahmadi-Nedushan, B., A. St-Hilaire, M. Bérubé, É. Robichaud, N. Thiémonge, and B. Bobée. (2006). A review of statistical methods for the evaluation of aquatic habitat suitability for instream flow assessment. River Research and Applications 22:503-523.

Arthington, A. H., S. E. Bunn, L. N. Poff, and R. J. Naiman. (2006). The Challenge of Providing Environmental Flow Rules to Sustain River Ecosystems. Ecol. Applic. 16:1311-1318.

Biggs, B. J. F., V. I. Nikora, and T. H. Snelder. (2005). Linking scales of flow variability to lotic ecosystem structure and function. River Research and Applications 21:283-298.

Bovee, K. D. (1982). A guide to stream habitat analysis using the Instream Flow Incremental Methodology., Fish and Wildlife Service FWS/OBS-82/26. 
Pollino et al., Ecohydrological modelling: guidance on selecting approaches

Bunn, S. E., and A. H. Arthington. (2002). Basic Principles and Ecological Consequences of Altered Flow Regimes for Aquatic Biodiversity. Environmental Management 30:492-507.

Burgman, M. A., D. R. Breininger, B. W. Duncan, and S. Ferson. (2001). Setting Reliability Bounds on Habitat Suitability Indices. Ecological Applications 11:70-78.

Elith, J., and J. R. Leathwick. (2009). Species Distribution Models: Ecological Explanation and Prediction Across Space and Time. Annual Review of Ecology, Evolution, and Systematics 40:677-697.

Frissell, C., W. Liss, C. Warren, and M. Hurley. (1986). A hierarchical framework for stream habitat classification: Viewing streams in a watershed context. Environmental Management 10:199-214.

Jakeman, A. J., R. A. Letcher, and J. P. Norton. (2006). Ten iterative steps in development and evaluation of environmental models. Environmental Modelling and Software 21:602-614.

Kearney, M., and W. Porter. (2009). Mechanistic niche modelling: combining physiological and spatial data to predict species' ranges. Ecology Letters 12:334-350.

Kennard, M. J., J. D. Olden, A. H. Arthington, B. J. Pusey, and N. LeRoy Poff. (2007). Multiscale effects of flow regime and habitat and their interaction on fish assemblage structure in eastern Australia. Canadian Journal of Fisheries and Aquatic Sciences 64:1346-1359.

Kingsford, R. T., and K. M. Auld. (2005). Waterbird breeding and environmental flow management in the Macquarie Marshes, arid Australia. River Research and Applications 21:187-200.

Merritt, D. M., M. L. Scott, N. LeRoy Poff, G. T. Auble, and D. A. Lytle. (2010). Theory, methods and tools for determining environmental flows for riparian vegetation: riparian vegetation-flow response guilds. Freshwater Biology 55:206-225.

Overton, I. C., C. Pollino, J. Roberts, J. R. W. Reid, N. R. Bond, H. M. McGinness, B. Gawne, Stratford D.S., L. E. Merrin, D. Barma, S. M. Cuddy, D. L. Nielsen, T. Smith, B. L. Henderson, D. S. Baldwin, G. S. Chiu, and T. M. Doody. (2014). Development of the Murray-Darling Basin Plan SDL Adjustment Ecological Elements Method. Report prepared for the Murray-Darling Basin Authority. CSIRO, Canberra.

Plagányi, É. E., J. D. Bell, R. H. Bustamante, J. M. Dambacher, D. M. Dennis, C. M. Dichmont, L. X. C. Dutra, E. A. Fulton, A. J. Hobday, E. Ingrid van Putten, F. Smith, A. D. M. Smith, and S. Zhou. (2011). Modelling climate-change effects on Australian and Pacific aquatic ecosystems: a review of analytical tools and management implications. Marine and Freshwater Research 62:1132-1147.

Poff, L. N., J. D. Allan, M. B. Bain, J. R. Karr, K. L. Prestegaard, B. D. Richter, R. E. Sparks, and J. C. Stromberg. (1997). The natural flow regime: A paradigm for river conservation and restoration. BioScience 47:769-784.

Poff, L. N., B. D. Richter, A. H. Arthington, S. E. Bunn, R. J. Naiman, E. Kendy, M. Acreman, C. Apse, B. P. Bledsoe, M. C. Freeman, J. Henriksen, R. B. Jacobson, J. G. Kennen, D. M. Merritt, J. H. O'Keeffee, J. D. Olden, K. Rogers, R. E. Tharme, and A. Warner. (2010). The ecological limits of hydrologic alteration (ELOHA): a new framework for developing regional environmental flow standards. Freshwater Biol. 55:147-170.

Richter, B. D., J. V. Baumgartner, R. Wigington, and D. P. Braun. (1997). How much water does a river need? Freshwater Biol. 37:231-249.

Ruggiero, L. F., G. D. Hayward, and J. R. Squires. (1994). Viability Analysis in Biological Evaluations: Concepts of Population Viability Analysis, Biological Population, and Ecological Scale. Conservation Biology 8:364-372.

Rykiel, E. J. (1996). Testing ecological models: the meaning of validation. Ecological Modelling 90:229-244.

Soberón, J., and M. Nakamura. (2009). Niches and distributional areas: Concepts, methods, and assumptions. Proceedings of the National Academy of Sciences 106:19644-19650.

Southwood, T. R. E. (1977). Habitat, the Templet for Ecological Strategies? Journal of Animal Ecology 46:337-365.

Swirepik, J., I. Burns, F. Dyer, I. Neave, M. O'Brien, G. Pryde, and R. Thompson. (2016). Establishing environmental water requirements for the Murray-Darling Basin, Australia's largest developed river system. River Research and Applications 32:1153-1165.

Tharme, R. (2003). A global perspective on environmental flow assessment: emerging trends in the development and application of environmental flow methodologies for rivers. River Research and Applications 19:397 - 441.

Ward, J. V., K. Tockner, and F. Schiemer. (1999). Biodiversity of floodplain river ecosystems: ecotones and connectivity. Regulated Rivers: Research \& Management 15:125-139.

Whited, D. C., M. S. Lorang, M. J. Harner, F. R. Hauer, J. S. Kimball, and J. A. Stanford. (2007). Climate, Hydrologic Disturbance, and Succession: Drivers of Floodplain Pattern. Ecology 88:940-953. 